American Journal of Applied Sciences 9 (4): 450-458, 2012

ISSN 1546-9239

(C) 2012 Science Publications

\title{
Biomarkers of Oxidative DNA Damage and Soluble Fas/Fas Ligand in Type 2 Diabetic Patients
}

\author{
${ }^{1}$ Mohamed H. Mahfouz, \\ ${ }^{1}$ Ibrahim A. Emara and ${ }^{2}$ Ghada A. Omar \\ ${ }^{1}$ Department of Biochemistry, \\ ${ }^{2}$ Department of Clinical and Chemical Pathology, \\ National Institute of Diabetes and Endocrinology, Cairo, Egypt
}

\begin{abstract}
Problem statement: Involvement of oxidative stress in the pathogenesis of diabetic complications has been proposed. 8-hydroxy-2'-deoxyguanosine (8-OHdG) has been reported to serve as a new sensitive biomarker of the oxidative DNA damage in vivo. Apoptosis via Fas/Fas Ligand (FasL) interactions has been proposed to be a major T-cell-mediated effector mechanism in autoimmune diabetes. This study was undertaken to investigate whether the serum levels of 8-OHdG and circulating soluble Fas/Fas Ligand, two transmembrane glycoproteins involved in apoptosis, are altered in patients with type 2 diabetes. Approach: 8-OHdG, sFas and sFasL were measured with the ELISA method in twenty normal controls (group I), thirty patients with type 2 DM (duration ranged from 1-3 years, group II) and in thirty patients with type 2 DM (duration ranged from 5-10 years, group III). Also, serum glucose (Fasting and postprandial), HbA1c, insulin, lipid profile (total cholesterol, triacylglycerol, HDL-c and LDL-c) and serum malondialdehyde (MDA) level were determined. Results: The patients with a long duration of diabetes were poorly controlled and had significantly higher levels of HbA1c $(\mathrm{p}<0.05)$ when compared to control group. Serum levels of total cholesterol, triacylglycerol and LDL-c were significantly higher $(\mathrm{p}<0.05)$ in diabetic patients in comparison with healthy normal control, while HDL-c level was significantly lower in both groups than in the control group ( $<<0.05)$. 8-OHdG and MDA levels were significantly higher in both diabetic groups than in the control group. sFas serum levels were significantly increased in both diabetic groups as compared with normal controls $\left(10.5 \pm 3.2,14.4 \pm 3.4 \mathrm{ng} \mathrm{mL}^{-1} \mathrm{Vs} 4.5 \pm 2.1 \mathrm{ng} \mathrm{mL}^{-1}, \mathrm{p}<0.05\right)$, but the levels were significantly higher in patients with long duration of diabetes when compared with that of short duration of diabetes $(\mathrm{p}<0.05)$. sFasL serum levels were less than $0.1 \mathrm{ng} \mathrm{mL}^{-1}$ in normal control group and the same results were observed in sera from groups of diabetic patients. A significant positive correlation was observed between 8-OHdG and each of HbA1c, MDA, HOMA index and sFas in diabetic group of long duration. On the other hand, there was a positive correlation between sFas levels and each of $\mathrm{HbA} 1 \mathrm{c}$, MDA and HOMA index. Also MDA was positively correlated with HbA1c and HOMA index. HbA1c was positively correlated with HOMA index. Conclusion: In type 2 diabetic patients, 8-OHdG could be a sensitive biomarker for evaluating oxidative DNA damage, there seems to be a dysregulation of apoptosis, as expressed by enhanced sFas levels, suggesting that these markers may be helpful for the early diagnosis of type 2 diabetic patients.
\end{abstract}

Key words: Type 2 diabetes, 8-hydroxy-2'-deoxyguanosine (8-OHdG), apoptosis, Reactive Oxygen Species (ROS), Malondialdehyde (MDA)

\section{INTRODUCTION}

Diabetes mellitus is characterized by increased production of Reactive Oxygen Species (ROS), sharp reduction in antioxidant defense and altered cellular redox status. Hyperglycemia, a key clinical manifestation of diabetes mellitus, not only generates more reactive oxygen species, but also attenuates antioxidative mechanisms by scavenging enzymes and substances (Zhang et al., 2011).

Oxidative stress, a potentially harmful imbalance between the level of pro-oxidants and anti-oxidants. It can cause cellular injury and tissue damage by promoting several reactions e.g., lipid perxidation,

Corresponding Author: Mohamed H. Mahfouz, Department of Biochemistry, National Institute of Diabetes and Endocrinology, Cairo, Egypt 
DNA damage, protein glycation (Amran et al., 2010; Maxwell, 1995). Lipid peroxides may increase the participation of advanced glycation end-products in the development of chronic vascular complications (Ceriello, 1997). The chemical modifications of proteins and lipids by ROS is speculated to contribute to the pathogenesis of diabetic complications (Giugliano et al., 1996; Green et al., 1992). ROS also causes base modifications and strand breaks in DNA (Richter, 1995). It increases the conversion of Deoxyguanosine $(\mathrm{dG})$ to 8-hydroxydeoxyguanosine (8$\mathrm{OHdG})$ in DNA which is linked to increased mitochondrial DNA deletions (Suzuki et al., 1999).

Indeed, when defense mechanisms cannot prevent the accumulation of ROS, there is an increase in cellular damage proteins, lipids and nucleic acids. Accumulation of such injury ultimately leads to cell death through necrotic or apoptotic mechanisms (Mughal and Kirshenbaum, 2011). Oxidative stress is a critical part of the apoptoting agent. If the DNA is severely damaged, the cell will undergo apoptosis (Shackelford et al., 1999). Proteins secreted by these cells including soluble Fas (sFas) and soluble Fas ligand (sFasL) circulate in small, but detectable amounts. Fas is generated by alternative messenger RNA splicing capable of encoding a soluble Fas molecule lacking the transmembrane domain (Swindall and Bellis, 2011), whereas sFasL is released in serum from membrane-bound FasL processed by a metalloproteinase (Musial and Zwolińska, 2011) and its ligand are typicall members of The Tumor Necrosis Factor (TNF) receptor super family.

Many studies have demonstrated that importance of Fas-mediated apoptosis in tumorigenesis (Chen et al., 2005). Fas (Apo-1 or CD95) is a cell-surface receptor that transduces apoptotic signals from Fas ligand (FasL). The Fas/Fas ligand system is a key regulating system responsible for activation of apoptosis in various cell types including cellular constituents of the vessel wall (Bennett, 2002; Cosson et al., 2005).

The aim of this study was designed to evaluate the oxidative DNA damage (8-hydroxydeoxyguanosine), in addition to elucidate the changes of Fas/Fas ligand levels to perdict the early diagnosis of type 2 diabetic patients.

\section{MATERIALS AND METHODS}

Materials: This cross sectional study population included 80 subjects. All subjects were divided into 3 groups:

- Group I; Control group: comprising 20 healthy subjects which matched with age and sex as the diabetic patients. They had no recognizable diseases or previous history of endocrine disturbances. They were clinically free from any abnormality. They were not receiving any medications.

- Group II; Diabetic group: including 30 patients with type 2 diabetes (diagnosis according to criteria of the ADA, 2006). Diabetes duration ranged from 1 to 3 years. The age ranged from 40 to 60 years.

- $\quad$ Group III; including 30 diagnosed type 2 diabetic patients are selected. Diabetes duration ranged from 5 to 10 years. The age ranged from 43 to 61 years. Diabetic patients were treated by oral hypoglycemic agents.

All patients and participants gave their informed consent for the study, which was approved by Research Ethical Committee of General Organization of Teaching Hospitals and Institutes, Cairo, Egypt. The following variables were recorded: age, BMI and blood pressure. BMI was calculated as weight divided by height squared $\left(\mathrm{kg} \mathrm{m}^{-2}\right)$. The cutoff point of abnormal BMI was $25 \mathrm{~kg} \mathrm{~m}^{-2}$ (WHO, 2004). Waist Circumference (WC) was measured, with the subject standing, at the level midway between the lower rib margin and the iliac crest (Reeder et al., 1996). Blood pressure measurements were performed by trained technicians or nurses with a mercury sphygmomanometer and the first and fifth Korotkoff sounds were recorded to represent the systolic and diastolic pressures. Three measurements were obtained on each occasion, at 5-min intervals and averaged. Hypertension was defined as present if the Systolic Blood Pressure (SBP) $\geq 140 \mathrm{~mm} \mathrm{Hg}$ or Diastolic Blood Pressure (DBP) $\geq 90 \mathrm{~mm} \mathrm{Hg}$, or use of medication for hypertension.

In all cases blood samples were taken after $12 \mathrm{~h}$ overnight fasting, this was followed by the ingestion of meals and a further blood samples were collected $2 \mathrm{~h}$ later (postprandial). Venous blood was collected in vacutainers without additive, allowed to clot for $30 \mathrm{~min}$ at room temperature and centrifuged at $3000 \mathrm{rpm}$ for 10 min to get serum for immediate measurement of glucose (fasting and postprandial) and lipid profile. Hemolysed samples were excluded.

The remaining serum of the control subjects, diabetic patients were separated from their whole blood, divided into aliquots and were stored at $-80^{\circ} \mathrm{C}$ until the measurement of insulin, MDA, 8hydroxydeoxyguanosine, sFas and FasL. Immediate determination of $\mathrm{HbA} 1 \mathrm{c}$ on EDTA containing whole blood.

Methods: Glucose, total cholesterol, triacylglycerol and HDL-c were determinated using the methods 
described by Barham and Trinder (1972); Allain et al. (1974); Fossati and Prencipe (1982) and Finley et al. (1978) respectively. LDL-c was calculated by the Friedewald et al. (1972) formula. HbA1c was assayed using ion-exchange High-Performance Liquid Chromatography (HPLC) with Bio-Rad Variant Hemoglobin Testing System (Bio-Rad Laboratories, USA) according to method of Lahousen et al. (2002). Levels of serum insulin were assayed by Chemiluminescence Immunoassay (CLIA) according to Gammeltoft (1984). Homeostasis Model Assessment (HOMA) correlates positively with insulin-resistance and was calculated from the formula: HOMA-IR = [fasting glucose $(\mathrm{mmol} / \mathrm{L}) \mathrm{x}$ fasting insulin (milliunits per liter)/22.5 (Matthews et al., 1985). Malondialdehyde (MDA) concentration was determined fluorometrically according to the method of $\mathrm{Li}$ and Chow (1994) with excitation at $515 \mathrm{~nm}$ and emission at $550 \mathrm{~nm}$ after isobutyl alcohol extraction. Serum 8hydroxydeoxyguanosine was measured quantitatively by Enzyme-Linked Immunosorbent Assay (ELISA) kit (BIOXYTECH ${ }^{\circledR}$ OXIS Health Products, Inc. USA) according to to the manufacturer's instructions. sFas concentration was assessed using the sFas Enzymelinked Immunosorbent Assay (ELISA) kit (Research and Diagnostic Systems, Minneapolis, USA), with a

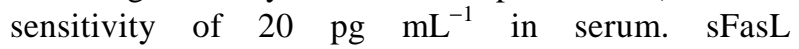
concentration was assayed using the sFasL ELISA kit (Medical \& Biological Laboratories, Nagoya, Japan), with a sensitivity of $0.1 \mathrm{ng} \mathrm{mL} \mathrm{mL}^{-1}$ in serum. All procedures were performed according to the manufacturer's instructions.

Statistical analysis: All results were expressed as the mean \pm SD. Statistical analysis was performed with Statistical Package for the Social Science for Windows (SPSS, version 11.0, Chicago, IL, USA). The data were analyzed by one-way Analysis Of Variance (ANOVA). To compare the difference among the groups, post hoc testing was performed by the Bonferroni test. The pvalue less than 0.05 were considered statistically significant (Dawson and Trapp, 2001).

\section{RESULTS}

The baseline characteristics of all the groups included in the study were summarized in Table 1. The diabetic studied groups and control group were comparable to each other with respect to age. A significant difference was detected between diabetic group and control group regarding BMI, $(\mathrm{p}<0.05)$ and
WC $(\mathrm{p}<0.05)$. It was also seen that, no significant difference was detected between diabetic groups studied regarding BMI and WC $(\mathrm{p}>0.05)$. Systolic and diastolic blood pressure were significant in the diabetic groups than control group. FBG, PPBG and HbA1c were significantly higher in the studied groups compared to control group as represented by $\mathrm{p}<0.05$. There were significant elevations in the level of serum insulin, HOMA index in diabetic studied groups compared to control group.

Table 2 demonstrates the changes of lipid profile of diabetic patient's type 2. Total Cholesterol (TC), triacylglycerol (TG) and LDL-c manifested significant elevations $(p<0.05)$ in diabetics as when compared to normal control subjects, while HDL-c level showed significant difference $(\mathrm{p}<0.05)$ among the study groups. TC, TG and LDL-c represented pronounced increases in diabetic patients with long duration compared to diabetic patients of short duration.

Table 3 showed the levels of $8-\mathrm{OHdG}$, sFas, sFasL and MDA in the diabetic groups and controls. 8-OHdG was higher in patients of diabetes mellitus as compared to controls. The level of sFas represented significant elevation $(\mathrm{p}<0.05)$ in both groups in comparison to normal subjects but long duration type 2 diabetic patients produced pronounced increase when compared to diabetic patients of short duration.

Table 1: Baseline characteristics of the subjects studied

\begin{tabular}{llll}
\hline Parameters & Group 1 & Group II & Group III \\
\hline Subjects (n) & 20.0 & 30.0 & 30.0 \\
Age (years) & $49.7 \pm 1.87$ & $50.3 \pm 1.31$ & $54.9 \pm 1.56$ \\
Duration of DM (years) & - & $2.9 \pm 0.38$ & $7.1 \pm 0.53^{\mathrm{b}}$ \\
BMI (kg m $\left.{ }^{-2}\right)$ & $22.92 \pm 1.19$ & $26.41 \pm 1.06^{\mathrm{a}}$ & $27.75 \pm 2.38^{\mathrm{b}}$ \\
WC $(\mathrm{Cm})$ & $94.55 \pm 11.78$ & $111.9 \pm 14.36^{\mathrm{a}}$ & $110.1 \pm 17.16^{\mathrm{b}}$ \\
SBP (mm Hg) & $118.5 \pm 7.83$ & $145.0 \pm 15.27^{\mathrm{a}}$ & $159.5 \pm 13.83^{\mathrm{b}}$ \\
DBP (mm Hg) & $76.5 \pm 5.29$ & $86.5 \pm 5.29^{\mathrm{a}}$ & $94.5 \pm 5.5^{\mathrm{b}, \mathrm{c}}$ \\
F.Glucose (mg/dL) & $77.5 \pm 8.94$ & $201.7 \pm 63.69^{\mathrm{a}}$ & $239.5 \pm 59.2^{\mathrm{b}}$ \\
P.P.Glucose (mg/dL) & $103.0 \pm 7.16$ & $292.2 \pm 58.04^{\mathrm{a}}$ & $359.9 \pm 70.88^{\mathrm{b}, \mathrm{c}}$ \\
HbA $_{1 \mathrm{c}}(\%)$ & $5.34 \pm 0.51$ & $7.86 \pm 0.84^{\mathrm{a}}$ & $9.53 \pm 0.78^{\mathrm{b}, \mathrm{c}}$ \\
F.Insulin (IU/L) $_{\text {HOMA index }}$ & $9.0 \pm 2.7$ & $12.7 \pm 1.8^{\mathrm{a}}$ & $14.4 \pm 1.5^{\mathrm{b}, \mathrm{c}}$ \\
HOMA & $2.6 \pm 0.53$ & $4.14 \pm 0.47^{\mathrm{a}}$ & $7.5 \pm 0.09^{\mathrm{a}, \mathrm{c}}$
\end{tabular}

The values expressed as mean \pm S.D., ${ }^{\mathrm{a}} \mathrm{p}<0.05$ Vs. Group I, ${ }^{\mathrm{b}} \mathrm{p}<0.05$ Vs. Group I, ${ }^{\mathrm{c}} \mathrm{p}<0.05$ Vs. Group II. BMI: Body mass index; DM: Diabetes Mellitus; SBP: Systolic blood pressure; DBP: Diastolic blood pressure; HbA1c: glycosylated $\mathrm{Hb}$. WC: Waist circumstance P.P.Glucose: Postprandial blood glucose HOMA: Homeostasis Model Assessment. Group I: Healthy subjects (Control group) Group II: Type 2 diabetic patients with duration ranged from 1-3 years. Group III: Type 2 diabetic patients with duration ranged from 5-10 years

Table 2: Serum lipid profile in different studied groups

\begin{tabular}{lcll}
\hline Parameters & Group I & Group II & Group III \\
\hline Total cholesterol (mg/dl) & $184.8 \pm 19.11$ & $288.6 \pm 29.72^{a}$ & $321.4 \pm 54.64^{b}$ \\
Triacyglycerol (mg/dl) & $92.1 \pm 18.07$ & $200.7 \pm 63.74^{a}$ & $273.7 \pm 58.34^{b, c}$ \\
HDL-c $(\mathrm{mg} / \mathrm{dl})$ & $47.8 \pm 8.625$ & $36.8 \pm 4.73^{a}$ & $37.0 \pm 9.04^{b}$ \\
LDL-c $(\mathrm{mg} / \mathrm{dl})$ & $117.18 \pm 18.01$ & $211.66 \pm 37.57^{a}$ & $229.66 \pm 50.55^{b}$ \\
\hline
\end{tabular}

The Values expressed as mean \pm S.D, ${ }^{a} \mathrm{p}<0.05$ Vs. Group I, ${ }^{b} \mathrm{p}<0.05$ Vs. Group I, ${ }^{c} \mathrm{p}<0.05$ Vs. Group II. HDL-c: High density lipoprotein-Cholesterol; LDL-c: Low density lipoprotein-Cholesterol 
Am. J. Applied Sci., 9 (4): 450-458, 2012

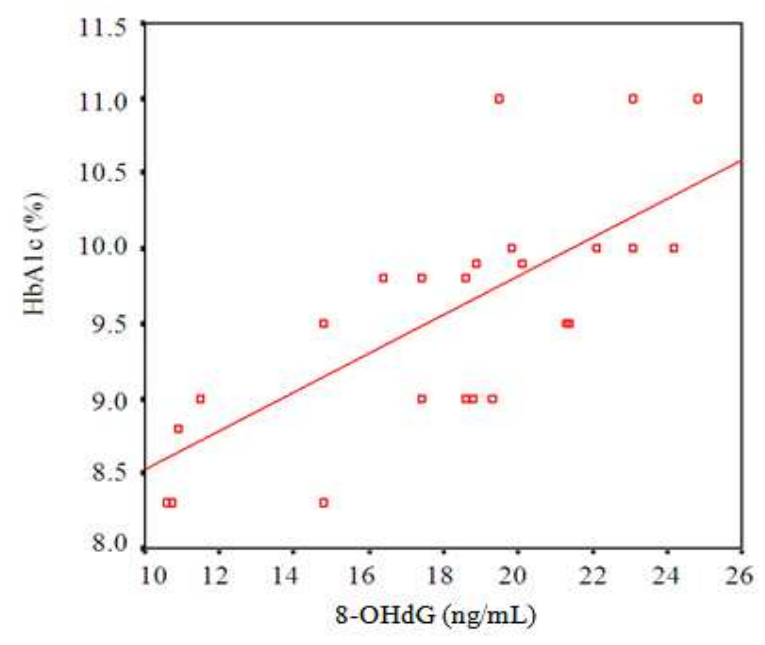

Fig. 1: Correlation between $8-\mathrm{OHdG}$ and $\mathrm{HbAlc}(\mathrm{r}=$ $0.771, \mathrm{p}<0.0001$ )

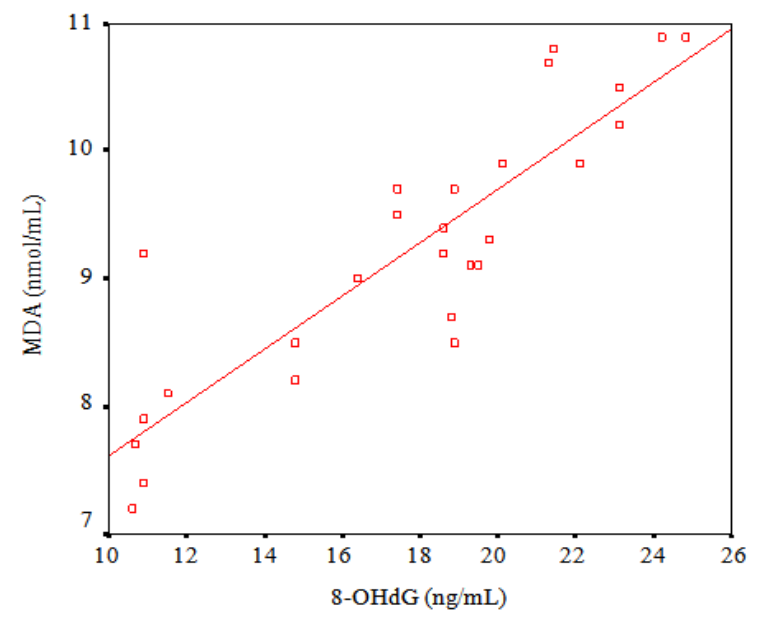

Fig. 2: Correlation between $8-\mathrm{OHdG}$ and MDA $(\mathrm{r}=$ $0.888, \mathrm{p}<0.0001$ )

The values obtained in serum from normal controls were less than $0.1 \mathrm{ng} \mathrm{mL}^{-1}$ and considered as normal. The same results were observed in sera from all groups of diabetic patients and also considered as normal. Serum MDA was significantly increased $(\mathrm{p}<0.05)$ in the both diabetic patient groups compared with controls. However the diabetic patients of long duration showed pronounced increase of MDA when compared to diabetic patients of short duration Table 3.

Pearson's correlation analyses revealed that, significant positive correlation was observed between 8-OHdG and HbA1c $(r=0.771, p=0.0001)$, MDA $(r=$ $0.888, \mathrm{p}=0.0001)$, HOMA index $(\mathrm{r}=0.606, \mathrm{p}=$ $0.0001)$ and $\mathrm{sFas}(\mathrm{r}=0.601, \mathrm{p}=0.0001)$ in diabetic group of long duration, as represented in Fig. 1- 4.

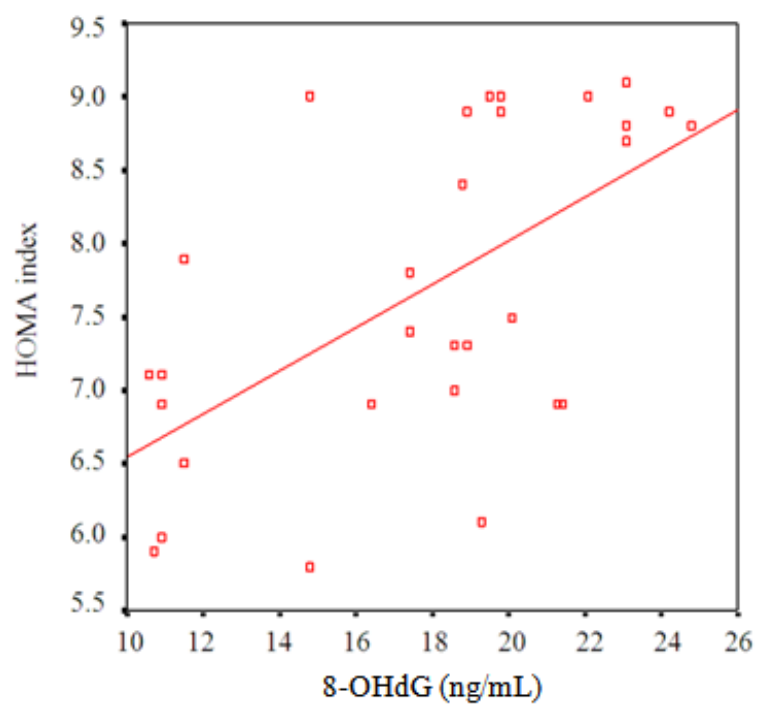

Fig. 3: Correlation between 8-OHdG and HOMA index $(\mathrm{r}=0.606, \mathrm{p}<0.0001)$

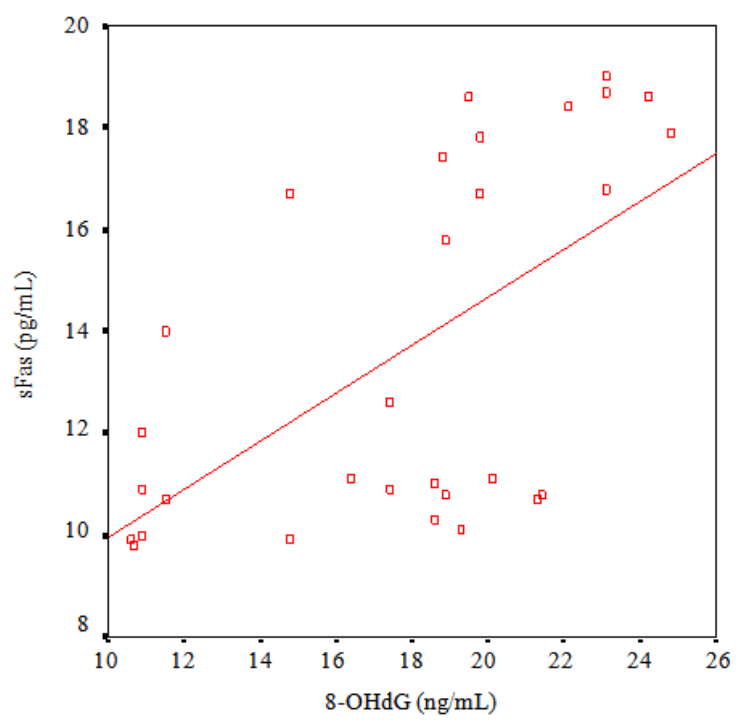

Fig. 4: Correlation between 8-OHdG and $\mathrm{sFas}(\mathrm{r}=$ $0.601, \mathrm{p}<0.0001$ )

Table 3: 8-hydroxydeoxyguanosine (8-OHdG), sFas, sFasL and Malondialdehyde (MDA) in different studied groups

\begin{tabular}{llll}
\hline Parameters & Group I & Group II & Group III \\
\hline $8-$ OHdG $(\mathrm{ng} / \mathrm{mL})$ & $5.1 \pm 1.828$ & $12.5 \pm 4.084^{\mathrm{a}}$ & $16.66 \pm 4.23^{\mathrm{b}, \mathrm{c}}$ \\
sFas $(\mathrm{pg} / \mathrm{mL})$ & $4.57 \pm 2.05$ & $10.45 \pm 3.15^{\mathrm{a}}$ & $14.43 \pm 3.44^{\mathrm{b}, \mathrm{c}}$ \\
Fas L $(\mathrm{pg} / \mathrm{mL})$ & Less than 0.1 & Less than 0.1 & Less than 0.1 \\
MDA $(\mathrm{nmol} / \mathrm{mL})$ & $4.7 \pm 0.22$ & $6.68 \pm 0.18^{\mathrm{a}}$ & $8.31 \pm 0.23^{\mathrm{b}, \mathrm{c}}$ \\
\hline \multicolumn{2}{l}{ The values expressed as mean \pm S.D. ${ }^{\mathrm{a}} \mathrm{p}<0.05$ Vs. Group I, ${ }^{\mathrm{b}} \mathrm{p}<0.05$} \\
Vs. Group I, ${ }^{\mathrm{c}} \mathrm{p}<0.05$ Vs. Group II. & sFas: Soluble form of Fas; sFasL: \\
Soluble form of Fas ligand &
\end{tabular}


Am. J. Applied Sci., 9 (4): 450-458, 2012

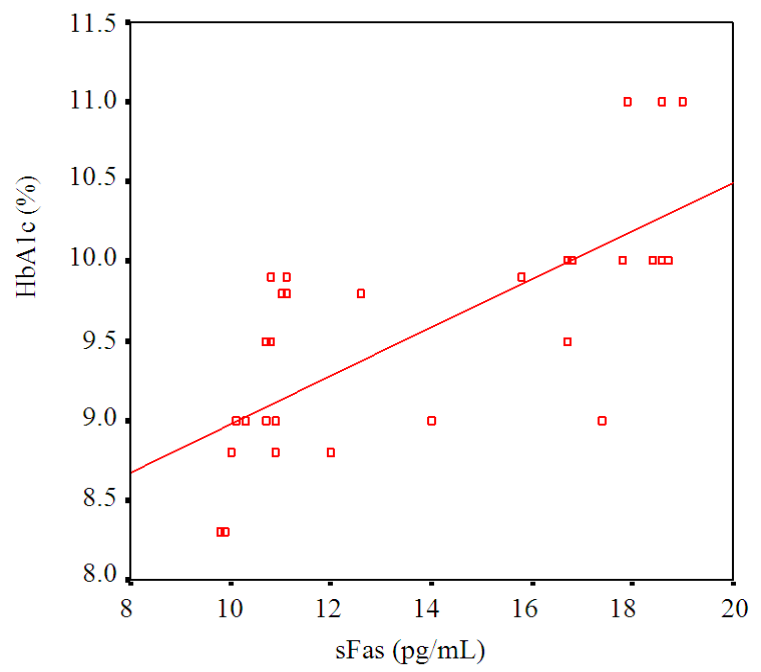

Fig. 5: Correlation between sFas and HbA1c $(r=0.714$, $\mathrm{p}<0.0001$ )

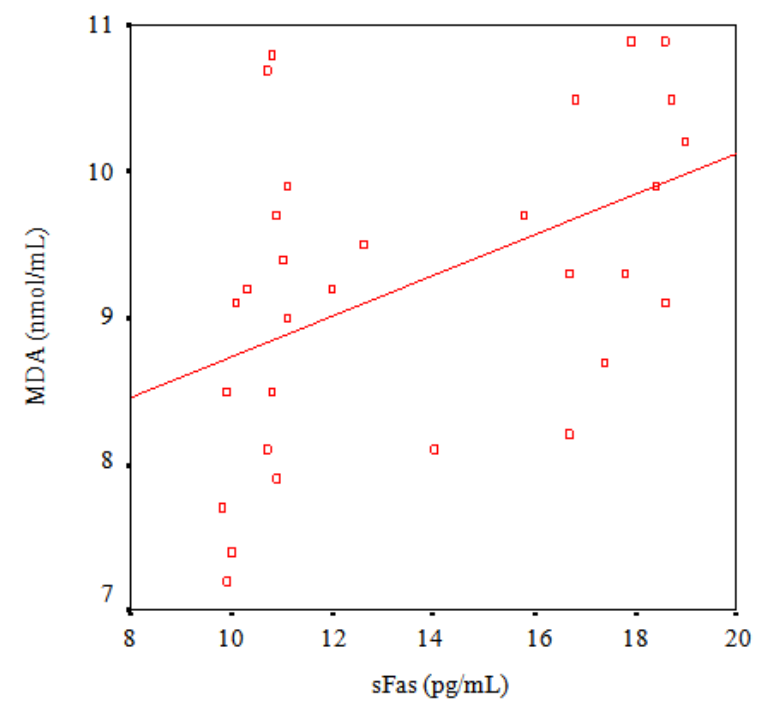

Fig. 6: Correlation between $\mathrm{sFas}$ and MDA $(r=0.463$, $\mathrm{p}<0.01)$

On the other hand, there was a positive correlation between sFas levels and HbA1c $(r=0.714, p=0.0001)$, MDA $(r=0.463, p=0.01)$ and HOMA index $(r=$ $0.927, p=0.0001)$ Fig. 5-7. Also MDA was positively correlated with HbA1c and HOMA index $(r=0.658, p$ $=0.001, r=0.484, p=0.007$, respectively) Fig. 8 and 9 . HbA1c was positively correlated with HOMA index ( $\mathrm{r}$ $=0.739, p=0.0001$ ) Fig. 10 .

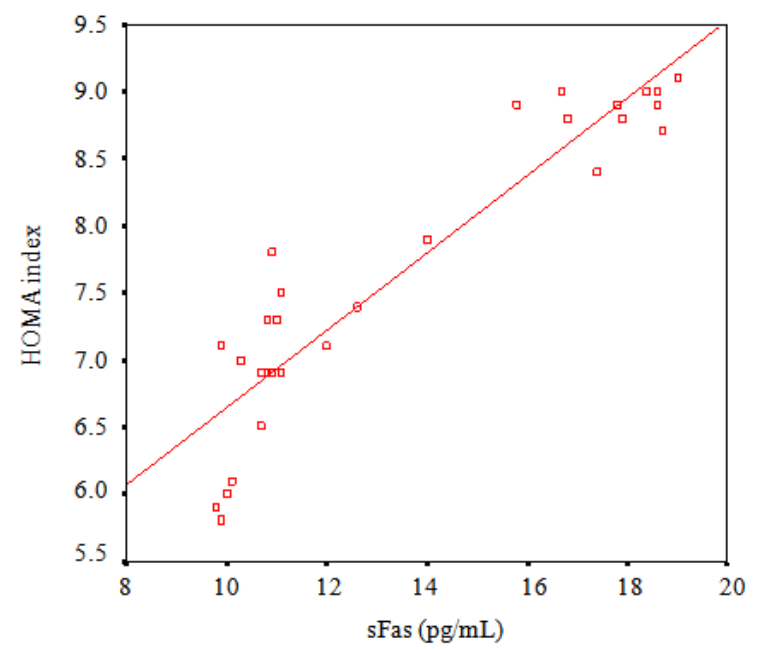

Fig. 7: Correlation between sFas and HOMA index $(\mathrm{r}=$ $0.927, \mathrm{p}<0.0001$ )

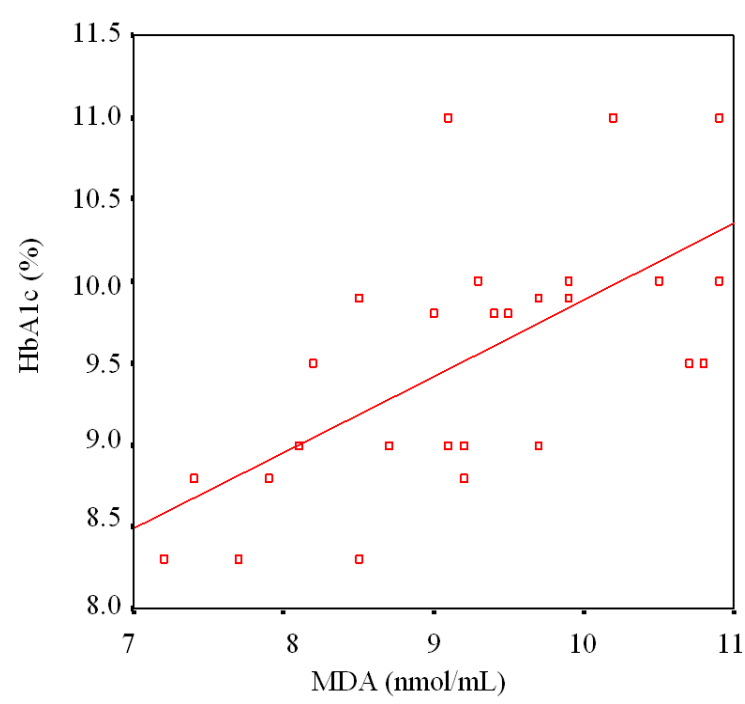

Fig. 8: Correlation between MDA and $\mathrm{HbA1c}(\mathrm{r}=$ $0.658, \mathrm{p}<0.001)$

\section{DISCUSSION}

Type 2 diabetes is characterized by hyperglycemia and dyslipidemia which associated with a cluster of risk factors forming the metabolic syndrome (Ram et al., 2003). Cardiovascular diseases are the cause of death up to $80 \%$ of patients with type 2 diabetes (Cosson et al., 2005).

In this study, the degree of insulin resistance was a higher in these diabetic patients by significant elevation of serum glucose, insulin levels and higher value of HOMA index as compared with control subjects. 
Am. J. Applied Sci., 9 (4): 450-458, 2012

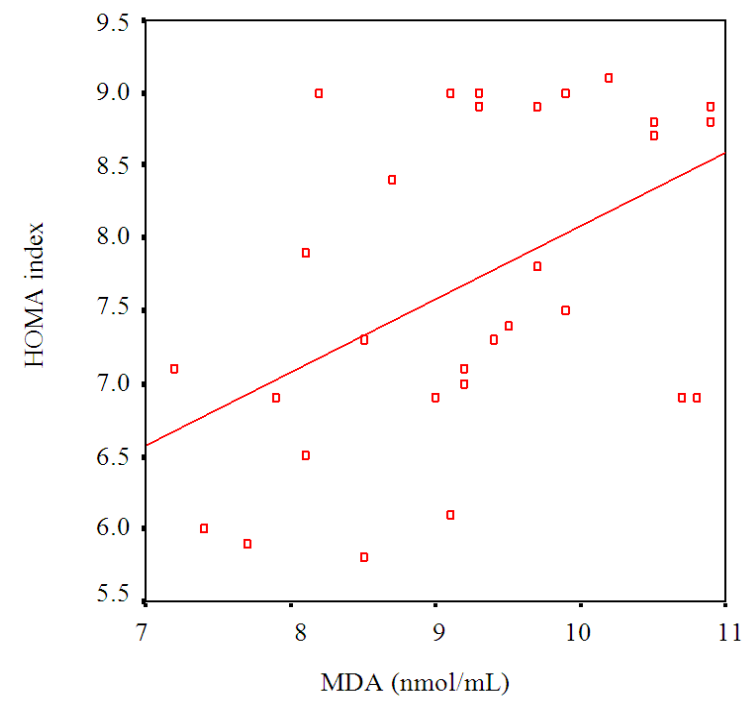

Fig. 9: Correlation between MDA and HOMA index (r $=0.484, p<0.007)$

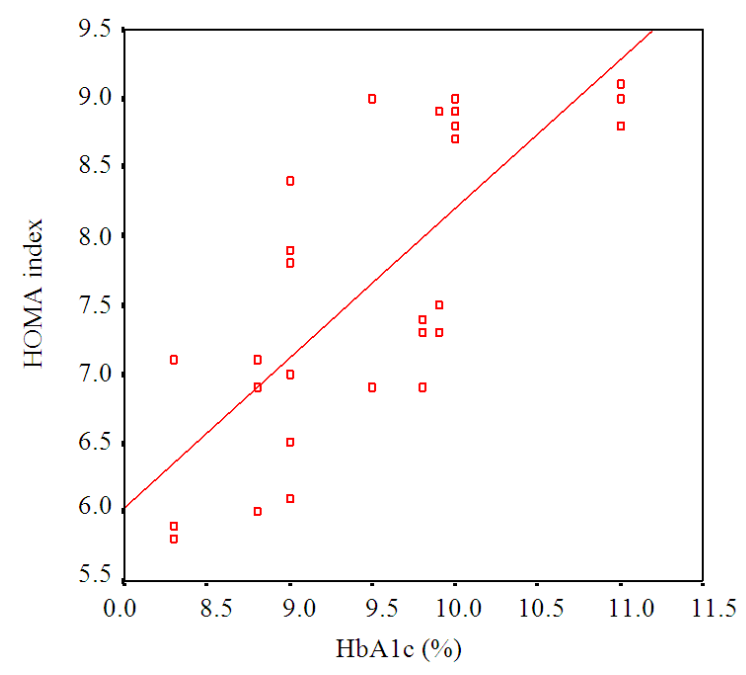

Fig. 10: Correlation between HbA1c and HOMA index $(\mathrm{r}=0.739, \mathrm{p}<0.0001)$

Insulin resistance has been attributed to how level of insulin-stimulated glucose oxidation due to modifications in the post-receptor cascade of insulin action (Catena et al., 2003). Also, there is a significant changes in glycating proteins $\mathrm{HbAlc}$ in the studied diabetic groups, this may be due to sufficient of time duration of the diabetics in the studied patients.

The dyslipidemia which observed in the present diabetic patients elucidated by significant elevation in plasma total cholesterol, triacylglycerol and LDL-c, while the plasma level of HDL-c was decreased markedly in diabetic groups compared to control one. These results agree with those of (Hallfrisch et al., 1983; Nardelli et al., 2011). These lipoprotein abnormalities which are due to reduction of lipoprotein lipase activity are held to be responsible for considerable cardiovascular diseases related morbidity and mortality (Krentz, 2003).

In the diabetic state, the generation of ROS is enhanced through the processes of glucose autooxidation and protein glycation (Baynes, 1991; Giugliano et al., 1996).

ROS cause lipid peroxidation and damage protein by chemical modifications through cross-linking and fragmentation. Therefore oxidative stress has been considered to contribute to the pathological processes of diabetic complications. The present results revealed significant elevation in the level of blood MDA. This elevation is more notable in long duration of diabetic type 2 and is due to increased peroxidation of lipid in plasma membranes (Kesavulu et al., 2001). These results demonstrated that diabetes mellitus produces significantly more free radicals depletes antioxidant enzymes causes chromosomal aberration and DNA damage. One of the products of DNA oxidation, 8hydroxyguaniosine $(8-\mathrm{OHdG})$ has relevant marker for this study of oxidative stress (Perez et al., 2002),

In this study, long duration periods of diabetes type 2 caused significant elevation of serum 8 -OHdG compared to those of short duration diabetic patients and also versus control subjects. These results are in line with those of (Cadenas et al., 1997; Perez et al., 2002) who reported that the formation of $8-\mathrm{OHdG}$ is considered to be useful biomarker of an index of oxidative damage of DNA. Because $8-\mathrm{OHdG}$ is a marker for oxidative damage to DNA, the present observations show that diabetic patients have significantly increased oxdatively damaged DNA compared with their respective controls.

Several reports have demonstrated that diabetes increases oxidative damage to DNA (Ha et al., 1994; Dandona et al., 1996). 8-OHdG is a product of oxidative DNA damage following specific enzymatic cleavage after 8-hydroxylation of the guanine base, it increase with aging (Kaneko et al., 1996), during carcinogensis (Ames, 1989), during radiotherapy (Erhola et al., 1997), in smokers (Loft et al., 1992) and in patients with diabetes (Dandona et al., 1996).

Lorenzi et al. (1986) reported that hyperglycemia causes glycosylation of DNA and decreases the DNA repair process human endothelial cells. Ha et al. (1994) reported that the level of $8-\mathrm{OHdG}$ was increased in the kidney of streptozotocin diabetic rats. Nishikawa et al. (2003) suggested that urinary $8-\mathrm{OHdG}$ is a useful 
marker of early micro- and macro vascular complications in type 2 diabetic patients. Therefore it is suggested that U8-OHdG could be a sensitive biomarker especially for the patients with early stages of diabetic complications.

Oxidative stress which induces by diabetic disease is a critical part of the apoptotic agent. Dysregulation of apoptosis has been implicated as an important factor mediating tissue turnover (Bennett, 2002). The Fas/FasL pathway may be involved (Liao et al., 2010).

In the current study, the sFas level was higher in a diabetic population which short and long duration than in subjects without diabetes. Furthermore, sFasL was found here to be undetectable accurately in the diabetic patients and control subjects. Cosson et al. (2005) demonstrated their study that sFas levels were higher in the diabetic patients than in the control subjects, sFasL was found to be undetectable in more than half the patients with diabetes versus the controls. They also reported that, in type 2 diabetic patients, hypertension was associated with a further increase of sFas and a further decrease of sFasL.

sFas is supposed to be a protector against atherosclerotic complications, since it inhibits the apoptosis of many cells, including leukocytes and vascular smooth muscle cells (Cheng et al., 1994).

In this line, sFas was found to be increases at the acute phase of myocardial infarction (Ohtsuka et al., 1999). This high level of sFas appeared to be an independent predictor of cardiovascular events in this population (Troyanov et al., 2003). Also, Blanco-Colio et al. (2007) reported that sFas concentrations are increased and sFasL are decreased in subjects at high cardiovascular risk suggesting that these patients may be noval marker of vascular injury.

A significant positive correlation was observed between 8-OHdG and each of HbA1c, MDA, HOMA index and sFas in diabetic group of long duration. On the other hand, there was a positive correlation between sFas levels and each of HbA1c, MDA and HOMA index. Also MDA was positively correlated with HbA1c and HOMA index. HbA1c was positively correlated with HOMA index.

\section{CONCLUSION}

In type 2 diabetic patients, $8-\mathrm{OHdG}$ could be a sensitive biomarker for evaluating oxidative DNA damage, there seems to be a dysregulation of apoptosis, as expressed by enhanced sFas levels, suggesting that these markers may be helpful for the early diagnosis of type 2 diabetic patients.

\section{REFERENCES}

Allain, C.C., L.S. Poon, C.S. Chan, W. Richmond and P.C. Fu, 1974. Enzymatic determination of total serum cholesterol. Clin Chem., 20: 470-475.

ADA, 2006. Diagnosis and classification of diabetes mellitus. Diabetes Care, 1: S5-S10. PMID: 14693921

Ames, B.N., 1989. Endogenous Oxidative DNA Damage, Aging and Cancer. Free Radic. Res. Commun., 7: 121-128.

Amran, A.A., Z. Zakaria, F. Othman and O. Morat, 2010. Effect of Garcinia Atroviridis on Oxidative Stress and Atherosclerotic Changes in Experimental Guinea Pigs. Am. J. Pharmacol. Toxicol., 5: 65-70. DOI: 10.3844/ajptsp.2010.65.70

Barham, D. and P. Trinder, 1972. An improved colour reagent for the determination of blood glucose by the oxidase system. Analyst, 97: 142-145. DOI: 10.1039/AN9729700142

Baynes, J.W., 1991. Role of oxidative stress in development of complications in diabetes. Diabetes, 40: 405-412. DOI: 10.2337/diabetes.40.4.405

Bennett, M.R., 2002. Apoptosis in the cardiovascular system. Heart, 87: 480-487. DOI: 10.1136/heart.87.5.480

Blanco-Colio, L.M., J.L. Mart-Ventura, E.D. Teresa, C. Farsang and A. Gaw et al., 2007. Increased Soluble Fas Plasma Levels in Subjects at High Cardiovascular Risk: Atorvastatin on Inflammatory Markers (AIM) Study, a Substudy of ACTFAST. Arterioscler Thromb. Vasc. Biol., 27: 168-174. PMID: 17053166

Cadenas, S., G. Barja, H.E. Poulsen and S. Loft, 1997. Oxidative DNA damage estimated by oxo8dG in the liver of guinea-pigs supplemented with graded dietary doses of ascorbic acid and alphatocopherol. Carcinogenesis, 18: 2373-2377. DOI: 10.1093/carcin/18.12.2373

Catena, C., G. Giacchetti, M. Novello, G. Colussi and A. Cavarape et al., 2003. Cellular mechanisms of insulin resistance in rats with fructose-induced hypertension. Am. J. Hypertens., 16: 973-978. PMID: 14573337

Ceriello, A., 1997. Acute hyperglycaemia and oxidative stress generation. Diabet Med., 14: S45-S49. DOI: 10.1002/(SICI)1096-9136(199708)14:3+<S45::AIDDIA444>3.0.CO;2-R

Chen, D., C. Duggan, D.E. Texada and Y. Deng, 2005. Induction of Caspase-dependant Apoptosis by Enterovirus 70 in Human Lens Epithelial SRA01/04 Cells. Am. J. Inf. Dis., 1: 90-106. DOI: 10.3844/ajidsp.2005.90.106 
Cheng, J., T. Zhou, C. Liu, J.P. Shapiro and M.J. Brauer et al., 1994. Protection from Fas-mediated apoptosis by a soluble form of the Fas molecule. Science, 263: 1759-1762. DOI: 10.1126/science.7510905

Cosson, E., A.F. Bringuier, J. Paries, R. Guillot and J. Vaysse et al., 2005. Fas/Fas-Ligand pathway is impaired in patients with type 2 diabetes. Influence of hypertension and insulin resistance. Diabetes Metab., 31: 47-54. DOI: 10.1016/S12623636(07)70166-0

Dandona, P., K. Thusu, S. Cook, B. Snyder and J. Makowski et al., 1996. Oxidative damage to DNA in diabetes mellitus. Lancet, 347: 444-445. DOI: 10.1016/S0140-6736(96)90013-6

Dawson, B. and R.G. Trapp, 2004. Basic and clinical biostatistics. 4th Edn., Lange Medical BooksMcGraw-Hill, New York, ISBN-10: 0071410171 pp: 438.

Erhola, M., S. Toyokuni, K. Okada, T. Tanaka and H. Hiai et al., 1997. Biomarker evidence of DNA oxidation in lung cancer patients: Association of urinary 8-hydroxy-2'-deoxyguanosine excretion with radiotherapy, chemotherapy and response to treatment. FEBS Lett., 409: 287-291. DOI: 10.1016/S0014-5793(97)00523-1

Finley, P.R., R.B. Schifman, R.J. Williams and D.A. Lichhti, 1978. Cholesterol in high-density lipoprotein: Use of $\mathrm{Mg} 2+/$ dextran sulfate in its enzymic measurement. Clin. Chem., 24: 931-933.

Fossati, P. and L. Prencipe, 1982. Serum triglycerides determined colorimetrically with an enzyme that produces hydrogen peroxide. Clin. Chem., 28: 2077-2080.

Friedewald, W.T., R.I. Levy and D.S. Fredrickson, 1972. Estimation of the concentration of lowdensity lipoprotein cholesterol in plasma, without use of the preparative ultracentrifuge. Clin. Chem., 18: 499-502.

Gammeltoft, S., 1984. Insulin receptors: Binding kinetics and structure-function relationship of insulin. Physiol Rev., 64: 1321-1378.

Giugliano, D., A. Ceriello and G. Paolisso, 1996. Oxidative stress and diabetic vascular complications. Diabetes Care., 19: 257-267. DOI: 10.2337/diacare.19.3.257

Green, D.A., A.A.F. Sima, M.J. Stevens, E.L. Feldman and S.A. Lattimer, 1992. Complications: Neuropathy, pathogenetic considerations. Diabetes Care, 15: 1902-1925. DOI: 10.2337/diacare.15.12.1902
Ha, H., C. Kim, Y. Son, M.H. Chung and K.H. Kim, 1994. DNA damage in the kidneys of diabetic rats exhibiting microalbuminuria. Free Radic. Biol. Med., 16: 271-274. DOI: 10.1016/08915849(94)90152-X

Hallfrisch, J., S. Reiser and E.S. Prather, 1983. Blood lipid distribution of hyperinsulinemic men consuming three levels of fructose. Am. J. Clin. Nutr., 37: 740-748.

Kaneko, T., S. Tahara and M. Matsuo, 1996. Nonlinear accumulation of 8-hydroxy-2'deoxyguanosine, a marker of oxidized DNA damage, during aging. Mutat Res., 316: 277-285. DOI: 10.1016/S0921-8734(96)90010-7

Kesavulu, M.M., B.K. Rao, R. Giri, J. Vijaya and G. Subramanyam et al., 2001. Lipid peroxidation and antioxidant enzyme status in Type 2 diabetics with coronary heart disease. Diabetes Res. Clin. Pract., 53: 33-39. DOI: 10.1016/S0168-8227(01)00238-8

Krentz, A.J., 2003. Lipoprotein abnormalities and their consequences for patients with type 2 diabetes. Diabetes Obes. Metab., 5: S19-S27. DOI: 10.1046/j.1462-8902.2003.0310.x

Lahousen, T., R.E. Roller, R.W. Lipp and W.J. Schnedl, 2002. Silent haemoglobin variants and determination of $\mathrm{HbA}_{1 \mathrm{c}}$ with the HPLC Bio-Rad Variant II. J. Clin. Pathol., 55: 699-703. DOI: 10.1136/jcp.55.9.699

Li, X.Y. and C.K. Chow, 1994. An improved method for the measurement of malondialdehyde in biological samples. Lipids, 29: 73-75. DOI: 10.1007/BF02537094

Liao, H., J. Xu and J. Huang, 2010. FasL/Fas pathway is involved in dengue virus induced apoptosis of the vascular endothelial cells. J. Med. Virol., 82: 1392-1399. DOI: $10.1002 /$ jmv. 21815

Loft, S., K. Vistisen, M. Ewertz, A. Tjn̈neland and K. Overvad et al., 1992. Oxidative DNA damage estimated by 8 -hydroxydeoxyguanosine excretion in humans: Influence of smoking, gender and body mass index. Carcinogenesis, 13: 2241-2247. DOI: 10.1093/carcin/13.12.2241

Lorenzi, M., D.F. Montisano, S. Toledo and A. Barrieux, 1986. High glucose induces DNA damage in cultured human endothelial cells. J. Clin. Invest., 77: 322-325. DOI: 10.1172/JCI112295

Matthews, D.R., J.P. Hosker, A.S. Rudenski, B.A. Naylor and D.F. Treacher et al., 1985. Homeostasis model assessment: Insulin resistance and $\beta$-cell function from fasting plasma glucose and insulin concentrations in man. Diabetologia, 28: 412-419. DOI: $10.1007 / \mathrm{BF} 00280883$ 
Maxwell, S.R., 1995. Prospects for the use of antioxidant therapies. Drugs, 49: 345-361. PMID: 7774511

Mughal, W. and L.A. Kirshenbaum, 2011. Cell death signalling mechanisms in heart failure. Exp. Clin. Cardiol., 16: 102-108. PMID: 22131851

Musial, K. and D. Zwolinska, 2011. Matrix metalloproteinases and soluble Fas/FasL system as novel regulators of apoptosis in children and young adults on chronic dialysis. Apoptosis, 16: 653-659. DOI: $10.1007 / \mathrm{s} 10495-011-0604-2$

Nardelli, T.R., R.A. Ribeiro, S.L. Balbo, E.C. Vanzela and E.M. Carneiro et al., 2011. Taurine prevents fat deposition and ameliorates plasma lipid profile in monosodium glutamate-obese rats. Amino Acids, 41: 901-908. DOI: 10.1007/s00726-0100789-7

Nishikawa, T., T. Sasahara, S. Kiritoshi, K. Sonoda and T. Senokuchi et al., 2003. Evaluation of urinary 8hydroxydeoxy-guanosine as a novel biomarker of macrovascular complications in type 2 diabetes. Diabetes Care., 26: 1507-1512. DOI: 10.2337/diacare.26.5.1507

Ohtsuka, T., M. Hamada, O. Sasaki, M. Suzuki and Y. Hara et al., 1999. Clinical implications of circulating soluble Fas and Fas ligand in patients with acute myocardial infarction. Coron Artery Dis., 10: 221-225. PMID: 10376200

Perez, D.D., P. Strobel, R. Foncea, M.S. Diez and L. Vasquez et al., 2002. Wine, Diet, Antioxidant Defenses and Oxidative Damage. Ann. N. Y. Acad. Sci., 957: 136-145. DOI: 10.1111/j.17496632.2002.tb02912.x

Ram, V.J., Farhanullah, B.K. Tripathi and A.K. Srivastava, 2003. Synthesis and antihyperglycemic activity of suitably functionalized 3H-quinazolin-4ones. Bioorg. Med. Chem., 11: 2439-2444. DOI: 10.1016/S0968-0896(03)00142-1
Reeder, B.A., L. Liu and L. Horlick, 1996. Selective screening for dyslipidemia in a Canadian population. J. Clin. Epidemiol., 49: 217-222. DOI: 10.1016/0895-4356(95)00063-1

Richter, C., 1995. Oxidative damage to mitochondrial DNA and its relationship to ageing. Int. J. Biochem. Cell Biol., 27: 647-653. DOI: 10.1016/1357-2725(95)00025-K

Shackelford, R.E., W.K. Kaufmann and R.S. Paules, 1999. Cell cycle control, checkpoint mechanisms and genotoxic stress. Environ. Health Perspect., 107: 5-24. PMID: 10229703

Suzuki, S., Y. Hinokio, K. Komatu, M. Ohtomo and M. Onoda et al., 1999. Oxidative damage to mitochondrial DNA and its relationship to diabetic complications. Diabetes Res. Clin. Pract., 45: 161168. DOI: $10.1016 / S 0168-8227(99) 00046-7$

Swindall, A.F. and S.L. Bellis, 2011. Sialylation of the Fas death receptor by ST6Gal-I provides protection against Fas-mediated apoptosis in colon carcinoma cells. J. Biol. Chem., 286: 22982-22990.

Troyanov, S., M.J. Hebert, M. Masse, N. Vigneault and I. Sirois et al., 2003. Soluble Fas: A novel predictor of atherosclerosis in dialysis patients. Am. J. Kidney Dis., 41: 1043-1051. DOI: 10.1016/S02726386(03)00202-6

WHO, 2004. Appropriate body-mass index for Asian populations and its implications for policy and intervention strategies. Lancet, 363: 157-163. DOI: 10.1016/S0140-6736(03)15268-3

Zhang, C., J. Liu, H. Pan, X. Yang and K. Bian, 2011. Mitochondrial dysfunction induced by excessive ROS/RNS-metabolic cardiovascular disease and traditional Chinese medicines intervention. Zhongguo Zhong Yao Za Zhi, 36: 2423-2428. 